ORIGINAL ARTICLE

\title{
Private vs. public self-consciousness and self-discrepancies
}

\author{
Adam Falewicz ${ }^{A, B, C, D, E, F}$, Waclaw Bak ${ }^{A, B, C, D, E, F}$ \\ Institute of Psychology, The John Paul II Catholic University of Lublin, Lublin, Poland
}

BACKGROUND

We studied the relationships of self-discrepancies with private and public self-consciousness. It was postulated that private self-consciousness is more strongly related to actual-ideal discrepancy than to actual-ought discrepancy, and that the latter is more strongly related to public self-consciousness.

\section{PARTICIPANTS AND PROCEDURE}

The sample consisted of 71 students aged 19-25, who completed the Self-Consciousness Scale and the DRP procedure for measuring self-discrepancies.

\section{RESULTS}

The results did not confirm the hypotheses, but revealed a correlation between actual-ideal discrepancy and social anxiety. It also turned out that private self-consciousness negatively correlates with the time of rating ideal-self attributes and positively with the time of rating ought-self attributes.

\section{CONCLUSIONS}

Self-consciousness may be related not so much to the size of self-discrepancies as to the accessibility of the content of each self-standard. The results are also consistent with the sequence of studies that challenge the central thesis of Higgins's theory concerning the specific relationship between actual-ought discrepancy and anxiety.

\section{KEY WORDS}

social anxiety; public self-consciousness; private self-consciousness; self-discrepancy

CORRESPONDING AUTHOR - Adam Falewicz, Institute of Psychology, The John Paul II Catholic University of Lublin, 14 Racławickie Avenue, 20-950 Lublin, Poland, e-mail: adamfalewicz@gmail.com

Authors' CONtribution - A: Study design · B: Data collection · C: Statistical analysis · D: Data interpretation ·

E: Manuscript preparation · F: Literature search · G: Funds collection

to Cite this ARticle - Falewicz, A., \& Bak, W. (2016). Private vs. public self-consciousness and self-discrepancies.

Current Issues in Personality Psychology, 4(1), 58-64.

RECEIVED 08.10.2015 - REVIEWED 08.11.2015 - ACCEPTED 17.11.2015 • PUBLISHED 07.12.2015 


\section{BACKGROUND}

The discrepancies in the structure of the self described by Higgins (1987) are the source of emotions such as anxiety, discomfort, sadness, depression, or a sense of guilt. Experiencing them is more or less conscious and puts individuals in a relationship with themselves and with others. On the other hand, the awareness of oneself and of the fact that one is embedded in social relations may secondarily become a perspective from which one looks at what one is like as well as what one would like to or ought to be like. The study presented in this article was conducted in order to answer the question of whether actual-ideal and actual-ought self-discrepancies are related to private and public self-consciousness (Fenigstein, 2009).

\section{SELF-KNOWLEDGE AND SELF-AWARENESS}

The distinction introduced by James (1890/1950) between "I" and "Me" - between the subject (I as a knower) and the object of cognition (empirical Me) - points to the fundamental difference in the human being between the subjective and objective aspects of self-experience. "I" emerges out of the sense of self-awareness, constantly explores, and is more or less aware of "Me". This makes it legitimate to speak of a kind of self-system, which has its structural aspect (the characteristics of the objective self) and its dynamic aspect (the activity of the subjective self).

The conscious and unconscious part of human behavior is subject to control by the self-system, referred to as self-regulation (Vohs \& Baumeister, 2004). One of the classic models of self-regulation is the theory of objective self-awareness by Duval and Wicklund (1972; Silvia \& Duval, 2001). When a person's attention is self-focused, the person becomes the object of his or her awareness - hence the expression objective self-awareness. When, by contrast, a person's attention is diverted from that person and focused on external reality, the individual experiences himself or herself as a source of perception and action, which the authors of the theory refer to as a state of subjective self-awareness. Activated by self-focus, the state of objective self-awareness leads to comparisons of the self with a particular standard. The self is understood here as a person's self-knowledge, and the standard is a mental representation of the desired attitudes, traits, and behaviors. Discrepancies between self-standards are always a source of negative emotions, which individuals try to reduce by using one of three strategies. They can change their behaviors towards greater conformity with the standard, modify the standard, or escape from the state of self-awareness (Silvia \& Duval, 2001; Snow \& Duval, 2004).
Duval and Wicklund (1972) understood selfawareness as a state that can be experimentally induced - a situational variable that influences the person's current functioning. However, there are also individual differences that may determine the way in which a given individual reacts to situations involving self-awareness (such as meditation, Rogerian therapy, or existential analysis). Thus understood, self-awareness has the features of a trait, being a relatively stable tendency to direct one's attention inwards or outwards (Fenigstein, 2009). In this approach it is assumed that there are people almost permanently focused on themselves by evaluating their own behavior. Such people more accurately assess their characteristics, as shown by the higher correspondence observed in their case between self-description and behavior (Fenigstein, 2009; Nasby, 1989). On the other hand, there are people characterized by very low insight stemming from self-awareness. When speaking of a trait, Fenigstein, Scheier, and Buss (1975) use the term self-consciousness, which they distinguish from self-awareness, the term reserved for a state. However, these phenomena are connected, and individuals high in self-consciousness tend to be more prone to the activation of self-awareness.

Two basic forms of self-consciousness are distinguished, which stems from the fact that a person can perceive themselves from two perspectives: their own and that of others (Carver, 2012; Fenigstein, 2009). The first form, called private self-consciousness, involves a focus on personal self-beliefs and a preoccupation with the inner world of feelings and thoughts, which enhances insight and increases the degree to which one is guided by personal standards. The other form is so-called public self-consciousness, which can be understood as a person's general awareness of themselves as a social individual. It is a focus on those aspects of the self that are shown to others and on external standards (Carver \& Scheier, 1980, 1985a). When constructing the questionnaire for measuring self-consciousness, its authors distinguished these two forms as well as an additional factor - social anxiety, defined as the discomfort experienced in the presence of other people (Carver \& Scheier, 1985a; Fenigstein, Scheier, \& Buss, 1975). While self-consciousness relates to focusing attention on oneself, social anxiety is associated with the reaction to this process and is, in a way, a by-product of attention being thus focused.

\section{SELF-CONSCIOUSNESS AND SELF-DISCREPANCIES}

The subject of two planes, private and public, on which a person functions also appears in Higgins's (1987) self-discrepancy theory. First, Higgins discuss- 
es the constructs of the actual self, the ideal self, and the ought self. The actual self is the way an individual perceives himself or herself currently. The ideal self corresponds to what kind of person one would like to be, and the ought self is what one should be like. Actual-ideal self-discrepancy leads to the emergence of feelings such as sadness, dejection, and depression, while actual-ought self-discrepancy generates anxiety, tension, or a sense of guilt (Higgins, 1987).

Second, Higgins's theory concerns the perspective from which an individual formulates the content of each of the above three aspects of self-knowledge. The individual's own perspective and the perspective of significant others are distinguished - meaning the points of view from which the person looks at himself or herself. In the case of adopting their own perspective, the person is guided by their own ideas and self-beliefs. When adopting other people's perspective, the individual uses his or her personal ideas about how others perceive and evaluate him or her.

When we analyze the self-discrepancy theory in the light of the conceptions of self-consciousness discussed above, certain analogies come to mind. It is possible to notice the compatibility of one's own perspective with private self-consciousness and the compatibility of the perspective of significant others with public self-consciousness. What is more, the very distinction between ideal and ought self-standards can be seen as linked with the private and public perspectives of looking at the self.

We postulate that actual-ideal discrepancy is more strongly related to private self-consciousness than actual-ought discrepancy (Hypothesis 1). Thinking about themselves, a person has a chance to notice more discrepancies between what he or she is like and what his or her own ideals are. The ideal self, representing personal hopes and dreams, should lend itself to such self-perception in which, performing a deeper analysis, an individual can see how far he or she is from his or her own ideals. Generating a larger self-discrepancy may stem from better insight in a person exhibiting a higher level of private self-consciousness (Nasby, 1989).

As regards the ought self, it is a cognitive representation of attributes that stem from a sense of duty and may actually be the requirements of the environment that have been internalized to different degrees, the environment being at the same time a kind of judge saying what kind of person one should be like. Consequently, an individual's tendency to focus on what others think about him or her may increase the distance of the actual self from the ought self to a greater extent than its distance from the ideal self. We therefore postulate that actual-ought discrepancy is more strongly related to public self-consciousness than actual-ideal discrepancy (Hypothesis 2). If a person intensively thinks about how others perceive him or her, then that person should notice that he or she fails to meet many of the internalized social requirements. As in the case of the first hypothesis, also here what is decisive is the individual's greater insight into the degree of fulfillment of ought self-standards - stemming, in this case, from high public self-consciousness (Carver \& Scheier, 1980).

\section{PARTICIPANTS AND PROCEDURE}

In order to test the hypotheses concerning the relationship of private and public self-consciousness with self-discrepancies, we conducted a questionnaire-based correlational study.

The participants were 79 university students representing various fields of study. We excluded the results of seven individuals from analyses on the grounds that they either filled out the questionnaires incompletely (i.e. by omitting one of the two measures) or did not follow the instructions for the measure of self-discrepancy (went very rapidly through the procedure without giving the real answers). Data from one additional participant were removed due to technical server error (the data were not recorded correctly). Eventually, we analyzed the results of 71 participants (including 45 women) aged from 19 to 25 years $(M=21.55, S D=1.40)$.

The study consisted in completing (a) the Self-Consciousness Scale by Fenigstein, Scheier, and Buss (1975; Zaborowski, 1989) and (b) the DRP procedure for measuring self-discrepancies (Bak, 2014). The Self-Consciousness Scale was administered in the standard paper-and-pencil form, whereas self-discrepancy measurement had an electronic form and was carried out via the Internet. Attached to the questionnaire sheets was the information about the online DRP as well as the data necessary to log in. The study was an element of a larger project, for the purpose of which the participants were additionally asked to complete the Coping Inventory for Stressful Situations (CISS) and to complete the DRP again after three weeks. Every participant received remuneration in the form of a cinema ticket voucher.

\section{SELF-CONSCIOUSNESS SCALE}

To measure self-consciousness, we used the Self-Consciousness Scale (SCS) by Fenigstein, Scheier, and Buss (1975; Carver \& Scheier, 1985a) as adapted into Polish by Zaborowski and Zwoliński (Zaborowski, 1989). The scale consists of 23 statements that participants responds to on a 5-point scale, indicating how accurately a given statement describes their experiences and behaviors - from 0 (totally inaccurate) to 4 (totally accurate). The questionnaire is divided into three scales, relating to: (a) private self-consciousness - 10 statements, e.g., "I reflect about myself a lot"; 
(b) public self-consciousness - 8 statements, e.g., "I'm usually aware of my appearance"; and (c) social anxiety - 5 statements, e.g., "I feel anxious when I speak in front of a group". In a study by the authors of the original version of the method, correlations between the Private and Public Self-Consciousness subscales were positive and low ( $r$ from .33 to .42 ; Fenigstein, 2009; Zaborowski, 1989). In our study, the correlation between the two variables was $r=.29, p=.014$. Additionally, we found a positive correlation between the Public Self-Consciousness and Social Anxiety scales $(r=.37, p=.002)$. The analysis of reliability in our study sample showed that all the subscales had an acceptable level of internal consistency: Cronbach's $\alpha=.65$ for Private Self-Consciousness; $\alpha=.70$ for Public Self-Consciousness; and $\alpha=.79$ for Social Anxiety.

\section{DRP - SELF-DISCREPANCY ASSESSMENT PROCEDURE}

Self-discrepancies were measured using the electronic DRP method (Bak, 2014), inspired by Higgins's research methodology (Higgins, Shah, \& Friedman, 1997). After a short training session demonstrating the technical aspects of the DRP procedure, the participant moves on to the questionnaire proper. In the first step, he or she is asked to answer four questions: (a) "What kind of person would you like to be?", (b) "What kind of person should you be?", (c) "What kind of person would you not like to be?", (d) "What kind of person should you not be?". For each of the four self-standards, the participant lists four attributes, which gives a 16-element self-description containing both desired and undesired aspects.

In the second step, the participant answers the question: "To what extent are you currently...?" referring to each of the 16 attributes generated. A horizontal line is displayed on the computer screen, with its ends labeled I am definitely not like this and I am definitely like this. The participant uses a virtual slider to indicate the degree to which he or she currently possesses a given attribute. The position of the slider is the measure of self-discrepancy, which the computer program codes in the form of a number from 0 to 100 . The average of measurement results for the four ideal-self attributes is the indicator of actual-ideal discrepancy. The average of measurement results for the four ought-self attributes is the indicator of the actual-ought discrepancy. The study also includes a measurement of discrepancies for attributes of the undesired self ("What kind of person I would not like to be") and the forbidden self ("What kind of person I should not be"). All the attributes are also rated in additional dimensions (e.g., "To what extent it is possible for me to be like this"; Bak, 2014), but this aspect of the study goes beyond the scope defined in the hypotheses, and the related data are not presented here.
Electronic measurement makes it possible not only to compute the size of self-discrepancies but also to register response times. Two indicators are particularly relevant in the context of the present study: (a) the mean time of rating ideal-self attributes in terms of the following questions: "To what extent are you currently like this?"; "To what extent is it possible for you to be like this?"; "To what extent should you be like this?"; (b) the mean time of rating ought-self attributes in terms of the following questions: "To what extent are you currently like this?"; "To what extent is it possible for you to be like this?"; "To what extent should you be like this?". Although we did not formulate hypotheses relating to these two variables, we included them in the analyses for exploratory purposes.

\section{RESULTS}

In order to test the hypotheses, we conducted correlational analyses to determine the associations between the SCS variables and self-discrepancies. The standard procedure in research concerning self-discrepancies is to use partial correlations rather than ordinary zero-order correlations (Higgins, 1987). This stems from the fact that self-discrepancies themselves are correlated with one another, which affects their unique relations with other variables. In the analyzed set of data, there was a significant correlation between actual-ideal and actual-ought self-discrepancies $(r=.59, p<.001)$, which justifies the use of partial correlations. We computed partial correlations between actual-ideal discrepancy and SCS while controlling for the effect of actual-ought discrepancy. Likewise, we computed partial correlations between actual-ought discrepancy and SCS while controlling for the effect of actual-ideal discrepancy.

We postulated that actual-ideal discrepancy was more strongly related to private self-consciousness than actual-ought discrepancy (Hypothesis 1), and that the latter was more strongly related to public self-consciousness (Hypothesis 2). The analyses (see Table 1) showed that there was no significant correlation between actual-ideal discrepancy and private self-consciousness. No correlation was found, either, between public self-consciousness and actual-ought discrepancy. In fact, neither of the two forms of self-consciousness correlated with either of the two types of self-discrepancy. Therefore, we must conclude that the hypotheses were not confirmed.

However, the additional analyses (Table 1) yielded an interesting result concerning the Social Anxiety scale, which is the third factor measured by the SCS. The partial correlation between actual-ideal discrepancy and anxiety with actual-ought discrepancy controlled for was statistically significant. By con- 
Table 1

The relations of private self-consciousness, public self-consciousness, and social anxiety scales with self-discrepancies - partial correlations

\begin{tabular}{rr}
$\begin{array}{c}\text { Actual-ideal } \\
\text { discrepancy }\end{array}$ & $\begin{array}{c}\text { Actual-ought } \\
\text { discrepancy }\end{array}$ \\
\hline
\end{tabular}

\begin{tabular}{lcc}
\hline Private self- & -.18 & .16 \\
consciousness & & .16 \\
Public self- & -.06 & .01 \\
consciousness & $.33^{* * *}$ & .00 \\
\hline
\end{tabular}

Note. Column I: partial correlations for actual-ideal self-discrepancy, with actual-ought discrepancy controlled for; column II: partial correlations for actual-ought self-discrepancy, with actual-ideal discrepancy controlled for; ${ }^{* * *} p<.001$.

trast, the partial correlation between actual-ought discrepancy and anxiety with actual-ideal discrepancy controlled for was close to zero.

For exploratory purposes, we also performed two additional analyses, in which we examined the relationships between the SCS scales and the variables relating to DRP response times. Two variables were taken into account: $\mathrm{tI}$ - the mean time of rating ideal-self attributes, and $\mathrm{tO}$ - the mean time of rating ought-self attributes. Before computing correlations, we excluded two outliers from the analysis. Because $\mathrm{tI}$ and tO were strongly correlated $(r=.87, p<.001)$, we used partial correlations also in these analyses. We computed partial correlations between the SCS variables and $\mathrm{tI}$ while controlling for the effect of tO. Likewise, we computed partial correlations between the SCS variables and tO while controlling for the effect of tI. The correlations presented in Table 2 show that neither public self-consciousness nor social anxiety is related to the time of rating the contents of self-standards. However, we found an interesting effect in the case of private self-consciousness. That scale correlates negatively with the time of rating the attributes of the ideal self and positively with the time of rating the attributes of the ought self. This means that the higher the level of private self-consciousness was, the faster the person rated ideal-self attributes and the slower he or she rated ought-self attributes.

\section{DISCUSSION}

The hypothesis that actual-ideal discrepancy is more strongly related to private self-consciousness than actual-ought discrepancy was not confirmed. The relationship between self-discrepancy and private self-consciousness turned out not to be significant in the case of either self-discrepancy. The same applies to the second hypothesis, in which we postulated
Table 2

The relations of private self-consciousness, public self-consciousness, and social anxiety scales with DRP response times - partial correlations

\begin{tabular}{lcc}
\hline & $\mathrm{tl}$ & $\mathrm{tO}$ \\
\hline Private self-consciousness & $-.25^{*}$ & $.36^{* *}$ \\
Public self-consciousness & .06 & .06 \\
Social anxiety & .05 & .03 \\
\hline
\end{tabular}

Note. $\mathrm{tl}$ - the mean time of rating ideal self attributes in terms of their current attainment, the expected possibility of their attainment, and the degree to which the person should attain them; tO - the mean time of rating ought self attributes in terms of their current attainment, the expected possibility of their attainment, and the degree to which the person should attain them. Column I: partial correlations for $\mathrm{tl}$, with tO controlled for; column II: partial correlations for $\mathrm{tO}$, with $\mathrm{tl}$ controlled for; ${ }^{*} p<.05 ;{ }^{* *} p<.01$.

that actual-ought discrepancy was more strongly related to public self-consciousness than actual-ideal discrepancy. These results are consistent with those obtained by Fromson (2006), who, similarly, found no relationship between self-consciousness and self-discrepancies. Instead, a moderating role of self-consciousness in the relationship between self-discrepancies and emotion was shown.

Seeking possible explanations for why our hypotheses were not confirmed, we should note that, according to the self-awareness theory, a person uses techniques that are supposed to put an end to self-discrepancies (Silvia \& Duval, 2001). It is therefore possible that self-consciousness involves the use of effective self-discrepancy control strategies, which is why high self-consciousness did not necessarily mean a large self-discrepancy in the structure of the self. This may be the case especially when private self-consciousness disturbs the level of self-esteem (Carver \& Scheier, 1985b) or gives rise to cognitive dissonance (Carver \& Scheier, 1980). A similar mechanism can be expected in the case of public self-consciousness and actual-ought discrepancy.

Although we did not detect the postulated relationship between self-consciousness and the size of self-discrepancies, it is possible that a different, interesting phenomenon occurs here, which is based on the relationship between self-consciousness and the cognitive accessibility of particular aspects of the self (see Higgins, 1996). When formulating our hypotheses, we expected that a high level of private self-consciousness would be associated with an increase in sensitivity to ideal-self contents, which are connected with adopting an internal, personal perspective to a greater extent than the ought self. In the case of public self-consciousness, we expected higher sensitivity to ought-self contents, which are more clearly related to adopting an external perspective of other people (sensitivity to social expectations, connected 
with the categories of duty and responsibility) than the ideal self. Further, our line of reasoning involved the expectation that this kind of "sensitizing" would result in observing a larger discrepancy between the actual self and a particular self-standard - the ideal self or the ought self, respectively. This sensitization may lead to more accurate assessment of the size of actual-ideal discrepancy (in the case of private self-consciousness) and actual-ought discrepancy (in the case of public self-consciousness). Because self-discrepancy may be large or small, its accurate assessment must take this diversity into account. If individuals high in self-consciousness accurately assess such diverse discrepancies, then indeed there is no reason to expect an association between self-consciousness and the size of the self-discrepancy.

Such an idea would be consistent with the thesis presented by Fenigstein (2009), who - analyzing the results of classic studies concerning private and public self-consciousness - concludes that self-consciousness is essentially an attention-based tendency. It directs the cognitive apparatus (attention, thinking) towards specific elements of the self, regardless of whether the person evaluates them as positive, negative, or neutral. As a result, neither public not private self-consciousness exhibits strong associations with any of the evaluative self-related variables.

A high level of private self-consciousness may therefore be related not so much to large actual-ideal discrepancy as to the cognitive accessibility of ideal-self contents as well as to the ease of retrieving them from memory (see Higgins, 1996). Likewise, a high level of public self-consciousness may be related not so much to large actual-ought discrepancy as to greater cognitive accessibility of ought-self contents. This line of reasoning - at least with regard to private self-consciousness - appears to be preliminarily confirmed by the results of the analyses examining the times devoted to the rating of ideal- vs. ought-self contents (see Table 2). It turned out that high private self-consciousness was associated with faster rating of ideal-self contents and with slower rating of ought-self contents. This suggests that ideal-self contents are more accessible for people high in private self-consciousness than ought-self contents. However, the results of our study did not prove that there is a greater cognitive accessibility of ought-self contents due to higher public self-consciousness. Thus, the empirical confirmation of our reasoning is, so far, partial and preliminary.

Apart from the analyses relating directly to the hypotheses, additional analyses revealed a relationship between the Social Anxiety scale and actual-ideal discrepancy. This finding draws attention as being basically at variance with Higgins's (1987) self-discrepancy theory (1987). Higgins claims that anxiety is uniquely related to actual-ought discrepancy and not related to actual-ideal discrepancy. The relations of self-discrepances with social anxiety obtained in our study are completely different. It turned out that anxiety was significantly associated with actual-ideal discrepancy and at the same time showed no association with actual-ought discrepancy. This result is in line with the sequence of studies that challenge Higgins's central theses concerning the specific relationship between the ought self and anxiety (e.g., Bruch, Rivet, \& Laurenti, 2000; Key, Mannella, Thomas, \& Gilroy, 2000; Ozgul, Heubeck, Ward, \& Wilkinson, 2003).

\section{REFERENCES}

Bak, W. (2014). Self-standards and self-discrepancies. A structural model of self-knowledge. Current Psychology, 33, 155-173.

Bruch, M. A., Rivet, K. M., \& Laurenti, H. J. (2000). Type of self-discrepancy and relationships to components of the tripartite model of emotional distress. Personality and Individual Differences, 29, 37-44.

Carver, C. S. (2012). Self-awareness. In: M. R. Leary, \& J. P. Tangney (eds.), Handbook of self and identity (pp. 50-68). New York: Guilford Press.

Carver, C. S., \& Scheier, M. F. (1980). Private and public self-attention, resistance to change, and dissonance reduction. Journal of Personality and Social Psychology, 39, 390-405.

Carver, C. S., \& Scheier, M. F. (1985a). The Self-Consciousness Scale: A revised version for use with general populations. Journal of Applied Social Psychology, 15, 687-699.

Carver, C. S., \& Scheier, M. F. (1985b). Self-consciousness and self-assessment. Journal of Personality and Social Psychology, 48, 117-124.

Duval, T. S., \& Wicklund, R. A. (1972). A theory of objective self-awareness. New York: Academic Press.

Fenigstein, A. (2009). Private and public self-consciousness. In: M. R. Leary, \& R. C. Hoyle (eds.), Handbook of individual differences in social behavior (pp. 495-511). New York: Guilford Press.

Fenigstein, A., Scheier, M. F., \& Buss A. H. (1975), Public and private self-consciousness: Assessment and theory. Journal of Consulting and Clinical Psychology, 43, 522-527.

Fromson, P. M. (2006). Self-discrepancies and negative affect: The moderating roles of private and public self-consciousness. Social Behavior and Personality, 34, 333-349.

Higgins, E. T. (1987). Self-discrepancy: A theory relating self and affect. Psychological Review, 94, 319-340.

Higgins, E. T. (1996). The "self digest": Self-knowledge serving self-regulatory functions. Journal of Personality and Social Psychology, 71, 1062-1083.

Higgins, E. T., Shah, J., \& Friedman, R. (1997). Emotional responses to goal attainment: Strength of 
regulatory focus as moderator. Journal of Personality and Social Psychology, 72, 515-525.

James, W. (1890/1950). The principles of psychology. New York: Dover.

Key, D. E., Mannella, M., Thomas, A. M., \& Gilroy, F. D. (2000). An evaluation of Higgins' self-discrepancy theory and an instrument to test its postulates. Journal of Social Behavior and Personality, 15, 303320.

Nasby, W. (1989). Private self-consciousness, selfawareness, and the reliability of self-reports. Journal of Personality and Social Psychology, 56, 950-957.

Ozgul, S., Heubeck, B., Ward, J., \& Wilkinson, R. (2003). Self-discrepancies: Measurement and relation to various negative affective states. Australian Journal of Psychology, 55, 56-62.

Silvia, P. J., \& Duval, T. S. (2001). Objective self-awareness theory: Recent progress and enduring problems. Personality and Social Psychology Review, 5, 230-241.

Snow, C. J., \& Duval, T. S. (2004). When the self stands out: Figure-ground effects on self-focused attention. Self and Identity, 3, 355-363.

Vohs, K. D., \& Baumeister, R. F. (2004). Understanding self-regulation. An introduction. In: R. F. Baumeister, \& K. D. Vohs (eds.), Handbook of self-regulation. Research, theory, and applications (pp. 1-9). New York/London: Guilford Press.

Zaborowski, Z. (1989). Psychospoteczne problemy samoświadomości [Psychosocial problems of self-consciousness]. Warsaw: PWN. 